\title{
Outbreak
}

\section{9-nCoV (Wuhan virus), a novel Coronavirus: human-to-human transmission, travel-related cases, and vaccine readiness}

\author{
Robyn Ralph ${ }^{1,2}$, Jocelyne Lew ${ }^{1}$, Tiansheng Zeng ${ }^{3}$, Magie Francis ${ }^{4}$, Bei Xue ${ }^{3,4}$, Melissa Roux ${ }^{4}$, Ali Toloue \\ Ostadgavahi ${ }^{4}$, Salvatore Rubino ${ }^{5}$, Nicholas J Dawe ${ }^{4}$, Mohammed N Al-Ahdal ${ }^{6}$, David J Kelvin ${ }^{3,4,7}$, \\ Christopher D Richardson ${ }^{4,7}$, Jason Kindrachuk ${ }^{8}$, Darryl Falzarano ${ }^{1,2}$, Alyson A Kelvin ${ }^{4,7,9}$ \\ ${ }^{1}$ Vaccine and Infectious Disease Organization - International Vaccine Centre (VIDO-InterVac), Saskatoon, \\ Saskatchewan, Canada \\ ${ }^{2}$ Department of Veterinary Microbiology, University of Saskatchewan, Saskatoon, Saskatchewan, Canada \\ ${ }^{3}$ International Institute of Infection and Immunity, Shantou University Medical College, Shantou, Guangdong, China \\ ${ }^{4}$ Department of Microbiology and Immunology, Faculty of Medicine, Dalhousie University, Halifax, Nova Scotia, \\ Canada \\ ${ }^{5}$ Sezione di Microbiologia Sperimentale e Clinica, Dipartimento di Scienze Biomediche, Università degli Studi di \\ Sassari, Sassari, Italy \\ ${ }^{6}$ Department of Infection and Immunity, King Faisal Specialist Hospital and Research Center, Riyadh, Saudi Arabia \\ ${ }^{7}$ Canadian Centre for Vaccinology, IWK Health Centre, Halifax, Nova Scotia, Canada \\ ${ }^{8}$ Laboratory of Emerging and Re-Emerging Viruses, Department of Medical Microbiology, University of Manitoba, \\ Winnipeg, Manitoba, Canada \\ ${ }^{9}$ Department of Pediatrics, Division of Infectious Disease, Faculty of Medicine, Dalhousie University, Halifax, Nova \\ Scotia, Canada
}

\begin{abstract}
On 31 December 2019 the Wuhan Health Commission reported a cluster of atypical pneumonia cases that was linked to a wet market in the city of Wuhan, China. The first patients began experiencing symptoms of illness in mid-December 2019. Clinical isolates were found to contain a novel coronavirus with similarity to bat coronaviruses. As of 28 January 2020, there are in excess of 4,500 laboratory-confirmed cases, with $>100$ known deaths. As with the SARS-CoV, infections in children appear to be rare. Travel-related cases have been confirmed in multiple countries and regions outside mainland China including Germany, France, Thailand, Japan, South Korea, Vietnam, Canada, and the United States, as well as Hong Kong and Taiwan. Domestically in China, the virus has also been noted in several cities and provinces with cases in all but one provinence. While zoonotic transmission appears to be the original source of infections, the most alarming development is that humanto-human transmission is now prevelant. Of particular concern is that many healthcare workers have been infected in the current epidemic. There are several critical clinical questions that need to be resolved, including how efficient is human-to-human transmission? What is the animal reservoir? Is there an intermediate animal reservoir? Do the vaccines generated to the SARS-CoV or MERS-CoV or their proteins offer protection against 2019-nCoV? We offer a research perspective on the next steps for the generation of vaccines. We also present data on the use of in silico docking in gaining insight into 2019-nCoV Spike-receptor binding to aid in therapeutic development. Diagnostic PCR protocols can be found at https://www.who.int/health-topics/coronavirus/laboratory-diagnostics-for-novel-coronavirus.
\end{abstract}

Key words: 2019-nCoV; coronavirus; Wuhan; human-to-human transmission; vaccine readiness.

J Infect Dev Ctries 2020; 14(1):3-17. doi:10.3855/jidc.12425

(Received 20 January 2020 - Accepted 23 January 2020)

Copyright $(\underset{2}{2020}$ Ralph et al. This is an open-access article distributed under the Creative Commons Attribution License, which permits unrestricted use, distribution, and reproduction in any medium, provided the original work is properly cited.

\section{Current State of emergency - Novel coronavirus outbreak in Wuhan, China \\ Wuhan 2019-nCoV}

A novel coronavirus (CoV) has emerged in Wuhan, China (Figure 1). This virus causes pneumonia of varying severity and has resulted in a high number of hospitalizations $(>4,500)$ and at least 105 deaths (casefatality rate (CFR) estimated at $1.5-3 \%)$. This virus is currently referred to as 2019-nCoV (also Wuhan virus) and is related to Severe Acute Respiratory Syndrome coronavirus (SARS-CoV), although with only approximately $80 \%$ similarity at the nucleotide level. With a seemingly comparable chain of events as the origin of SARS-CoV, the initial infections with 2019$\mathrm{nCoV}$ appears to be linked to contact with animals in wet markets. Even though human-to-human 
transmission was first thought to not be a mode of transmission, there are several documented cases that support that 2019-nCoV is capable of human-to-human transmission [1].

Atypical pneumonia of unexplained cause was first reported on 30 December 2019 in Wuhan city, the capital of Hubei province in central China. Initially, four cases were noted which presented with fever (greater than $38^{\circ} \mathrm{C}$ ), malaise, dry cough, and shortness of breath. Imaging was consistent with pneumonia or acute respiratory distress syndrome (ARDS) and patients had either reduced or normal white blood cell counts. An early link to the Wuhan South China Seafood City (also known as the South China Seafood Wholesale Market or the Huanan Seafood Market) was identified as a common factor in four of the patients. Treatment with antibiotics did not improve their condition over the next 3-5 days and a viral etiology was suspected. The patients were placed in isolation conditions. On 31 December 2020, it was announced that 27 cases of pneumonia, with 7 severe cases, had

Figure 1. Timeline of events and reported cases concerned with undiagnosed pneumonia and 2019-nCoV first identified in Wuhan, China.

\section{A.}

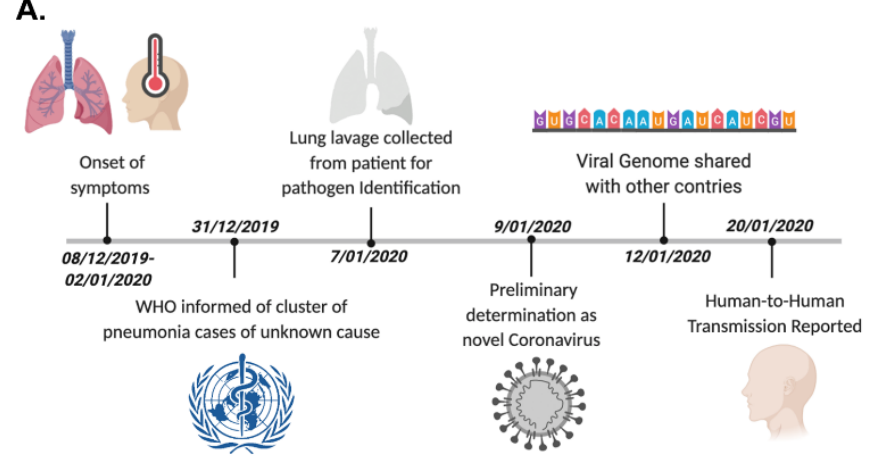

B.



The timeline of events concerning undiagnosed pneumonia, virus identification, and evidence of human-to-human transmission are shown (A). The number of reported cases plotted over time is shown (B). Case report numbers are acquired from ProMed and National Health Commission of the People's Republic of China. been identified [2]. Most of the patients were stall workers at Wuhan South China Seafood City. The market is reported to contain other animals such as birds (chickens, pheasants), bats, hedgehogs, marmots, tiger frogs, and snakes, as well as organs from rabbits and other animals. The market was closed on 1 January 2020 for environmental sanitation and disinfection and has not reopened [3].

By 3 January 2020, the cumulative number of cases rose to 44, with 11 in critical conditio and 121 close contacts of infected patients being monitored. At this point influenza virus, avian influenza virus, and adenovirus had been ruled out [4]. As of 5 January 2020, the number of cumulative cases increased to 59 (with onset between 8 December 2019 and 2 January 2020), and 163 close contacts being followed. At this time, SARS-CoV and MERS-CoV were ruled out as the causative agent. The number of cumulative cases increased to 59 on 5 January 2020 [5].

On 8 January 2020, it was reported that a novel coronavirus had been sequenced from one patient and subsequently identified in some of the other patients with pneumonia [6], later reported as 15 of the 59 patients [7]. The first report that some of the cases came from family clusters was the first suggestion that there may have been human-to-human transmission [8]. Virus isolation from one patient was reported [9]. The genome was made publicly available on 11 January 2020 on virological.org and later deposited into GenBank.

Additional updates should help clarify the incidence of human-to-human transmission. Given the rapid increase in case numbers, contact tracing will be vital to understanding the extent of human-to-human transmission and the possibility that 2019-nCoV mutations generate viruses with a greater potential for human-to-human transmission. It is important to note that in a Wuhan hospital cluster, 14 healthcare workers were infected by a 2019-nCoV patient [1]. This is reminiscent of several cases of healthcare workers infected by SARS-CoV and MERS-CoV patients. Hospital staff and Infectious Disease control should take necessary precautions in handling of 2019-nCoV patients (see WHO guidelines for handling of suspected and confirmed patients).

\section{Travel-related cases}

Another similarity to the SARS-CoV and the MERS-CoV epidemics is the occurrence of travelrelated cases. On 13 January 2020, a single case of 2019-nCoV was reported in Thailand of a person who had travelled from Wuhan [10]. This person was not 
reported to have been to the previously involved market, but had visited other markets [11]. The next day, a single case was reported in Japan, again following travel to Wuhan. This person reported no contact with the market, but possible contact with persons with pneumonia [12]. A second case, again originating from Wuhan, was identified in Thailand with no connection to other cases. One suspect case in Nepal with travel linked to Wuhan was also reported but not confirmed[8]. On 20 January 2020, a Chinese national, who had travelled from Wuhan, was identified as having 2019-nCoV upon arrival in South Korea and was quarantined [13]. Several airports in Asia and North America have now set up thermal screening at airports to detect possible 2019-nCoV infected individuals. On 21 January 2020, a 2019-nCoVinfected individual was identified in the state of Washington, USA [14]. This patient had also travelled to Wuhan but returned prior to the addition of thermal airport screening.

\section{Current state of knowledge and knowledge gaps}

The number of cases in Wuhan continued to increase due to retrospective testing, new cases, and changes in diagnostic evaluation for etiological agents [15]. By 28 January 2020, numerous cases had been identified in throughout China including Taiwan and Hong Kong. As of 28 January 2020, over 4,500 confirmed cases have been reported with $>100$ deaths (National Health Commission of the PRC). Human-tohuman transmission was suspected early in the outbreak and has now been confirmed and is the main source of infections [14] (National Health Commission of the PRC, update January 22, 2020). Many clinical questions remain unresolved at this time and await reporting and future publications. Some critical questions include: Do all infected individuals show symptoms? What is the frequency of asymptomatic infections? What is the time from exposure to onset of symptoms? Are asymptomatic individuals infectious? Is human-to-human transmission linked to specific mutations in the 2019-nCoV virus?

The extent of the outbreak geographically and epidemiologically currently remains unclear. To facilitate laboratory diagnosis of suspect cases of 2019$\mathrm{nCoV}$, the WHO has published guidelines for Laboratory testing for 2019 novel coronavirus (2019$n \mathrm{CoV})$ in suspected human cases (https://www.who.int/healthtopics/coronavirus/laboratory-diagnostics-for-novelcoronavirus) [15]. At the same website PCR primer sets can be found for diagnostic testing. These primer sets and protocols were developed by Hong Kong University and the CDC, China. An additional PCR protocol by V. Corman, T. Bleicker, S. Brünink, C. Drosten (Charité Virology, Berlin, Germany) O. Landt, (Tib-Molbiol, Berlin, Germany) M. Koopmans (Erasmus MC, Rotterdam, The Netherlands) and M. Zambon (Public Health England, London) can be found on the WHO website.

\section{Clinical Disease and Pathogenesis of 2019- nCov and other Coronaviruses}

The clinical picture

Coronaviruses are endemic in the human population and are responsible for up to $30 \%$ of annual respiratory infections resulting in rhinitis, pharyngitis, sinusitis, bronchiolitis, and pneumonia [16,17]. While primarily associated with relatively mild, self-limiting respiratory infections, infection from these viruses can result in severe disease in neonates, the elderly, and those with underlying comorbidities [18]. However, coronaviruses are now considered potential threats to global public health following the emergence of SARS-CoV in 2002 (9\% CFR), and MERS-CoV in 2012 (35\% CFR).

Early clinical manifestations of MERS and SARS are largely similar. Influenza-like symptoms accompanied by fevers, chills, dry cough, headache, malaise, and dyspnea were common early in the disease course in SARS patients [19]. The mean incubation period was estimated as 4.6 days with a range of 2 to 8 days between symptom onset and hospitalization. The mean time from symptom onset to death in fatal cases was 23.7 days [20]. Fatal outcomes were most frequent in those $>60$ years of age $(43 \%$ CFR). No fatalities were reported in young children and adolescents and fatal disease was reported in $6.8 \%$ of patients $<60$ years of age. Phase 1 of SARS was associated with increasing viral load and early disease symptoms (fever, malaise). Phase 2 was characterized by fever, hypoxemia, and decreasing viral loads, while radiographic progression of pneumonia was common. Twenty percent of patients progressed to acute respiratory distress syndrome (ARDS). Common laboratory features of SARS included lymphopenia, thrombocytopenia, disseminated intravascular coagulation, and elevated lactate dehydrogenase and creatine kinase levels [2022]. Acute renal impairment and proteinuria were associated with $6.7 \%$ and $84 \%$ of patients, respectively [21].

Early symptoms of MERS include fever, chills, cough, shortness of breath, myalgia, and malaise following a mean incubation period of 5 days, with a range of 2 to 13 days [23]. The median times from 
symptom onset to hospitalization, ICU admission, and death are 4, 5, and 11.5 days, respectively [24]. Symptomatic MERS patients present with a rapidly progressing pneumonia requiring mechanical ventilation and additional organ support within the first week of disease[20]. Severe and fatal disease is strongly linked to underlying comorbidities including diabetes mellitus, hypertension, obesity, and chronic cardiac, pulmonary, or renal disease[23]. Laboratory abnormalities include lymphopenia, leukopenia, thrombocytopenia, elevated serum creatinine levels consistent with acute kidney injury, and elevated liver enzymes [23,25-28]. High lactate levels and consumptive coagulopathy have also been reported $[25,29]$. Chest radiographic abnormalities are observed in most cases and the findings are consistent with viral pneumonitis, secondary bacterial pneumonia, or acute respiratory distress syndrome $[23,25,28,30,31]$.

\section{Therapeutics and supportive care}

Currently, supportive care is the only treatment option for patients with severe SARS or MERS illness and there are no licensed therapeutics or vaccines. There are, however, several vaccine candidates as well as antiviral candidates for prophylactic and therapeutic treatment of SARS-CoV and MERS-CoV infections. Mechanical ventilation and pulmonary rescue therapy were utilized for SARS but have had limited benefit for MERS patients [32]. Extracorporeal membrane oxygenation has been employed for MERS though its use is limited due to numerous factors [26]. Renal replacement therapy has been used extensively in MERS treatment $[25,33,34]$. The efficacy of a variety of antiviral therapeutics has been investigated for MERS with limited success. Moderate improvements in clinical outcomes were noted in common marmosets treated with a combination of lopinavir (LPV) and ritonavir (RTV) [35]. Additional investigations of interferon (IFN) antiviral activity in vitro have demonstrated that IFN beta (IFNb) had superior activity as compared to other IFN types [36,37]. A randomized control trial investigating the efficacy of LPV/RTVIFNb in MERS patients is currently ongoing [38].

\section{Coronavirus biology and Coronavirus outbreak cycles}

Molecular virology

Family Coronaviridae (order Nidovirales) is comprised of the Coronavirinae and Torovirinae subfamilies of viruses. Coronaviruses are enveloped RNA viruses with positive-sense RNA genomes ranging from 25.5 to $\sim 32 \mathrm{~kb}$ in length. The spherical virus particles range from $70-120 \mathrm{~nm}$ in diameter with four structural proteins. The viral envelope is covered by characteristic spike-shaped glycoproteins (S) as well as the envelope (E) and membrane (M) proteins. The $\mathrm{S}$ protein mediates host cell attachment and entry. The helical nucleocapsid, comprised of the viral genome encapsidated by the nucleocapsid protein $(\mathrm{N})$, resides within the viral envelope. The 5' two-thirds of the coronavirus genome consists of the replicase complex (ORF1a and ORF1b) and codes for two large polyproteins, ppla and pp1b. The viral replicasetranscriptase complex is made up of 16 non-structural proteins (nsp1-16) encoded for by the polyproteins pp1a and pp1ab. Both polyproteins can be cleaved by the viral proteases PLpro (nsp3) and 3CLpro (nsp5). The non-structural proteins function in the formation of double-membrane vesicles derived from the rough endoplasmic reticulum, and are the sites of viral replication and transcription [20]. Coronaviruses also encode a unique proofreading exoribonuclease (ExoN) function of nsp14 that reduces the accumulation of mutations in the RNA genome. The remainder of the genome is transcribed into a nested set of subgenomic mRNAs. Five accessory proteins (ORF3, ORF4a, ORF4b, ORF5 and ORF8b) are also encoded; however, they are not required for replication but may play a role in pathogenesis. Remaining subgenomic RNAs encode for accessory proteins that have immunomodulatory properties or functions that remain unknown.

\section{Coronavirus animal reservoirs and incidental hosts}

Determining the animal reservoir and incidental hosts of a virus with evidence of zoonosis such as 2019$\mathrm{nCoV}$ is important for controlling spillover events and limiting human infections. Although the ecological reservoir for both MERS-CoV and SARS-CoV remain undefined, evidence of viral presence in a variety of animal species has been found. Serologic evidence and the isolation of viral genomic material for SARS-CoVrelated viruses have provided evidence for bats as the putative reservoir for SARS-CoV. While masked palm civets and raccoon dogs were involved in transmission to humans and initially considered potential reservoirs, they are now considered as incidental or spillover hosts [39-41]. In contrast, dromedary camels are considered to act a reservoir host for MERS-CoV, and over half of primary human infections report contact with camels, however, it is suspected that bats are likely the ancestral host for MERS-CoV or a MERS-CoV-like virus $[42,43]$. Zoonotic transmission of SARS-CoV likely results from direct contact with intermediate hosts [44], while human-to-human transmission of both viruses 
occurs primarily through close contact and nosocomial transmission via respiratory secretions $[45,46]$. Considering the animals implicated as reservoir hosts for SARS-CoV and MERS-CoV, along with the conclusions from phylogenetic analyses from us and other groups, these potential reservoirs will be important starting points for investigation of the virus source.

\section{Molecular Analysis of 2019-nCoV}

The CoV Spike protein and host receptors

The coronavirus spike protein mediates coronavirus entry into host cells. The S1 subunit of spike contains the receptor binding domain, which binds to receptors on host cells and dictates virus tropism. Viral entry is mediated through viral and host membranes undergoing fusion via the S2 subunit of the spike protein [47]. Therefore, we analyzed and discuss the S1 domains, in particular the RBD, due to its role in determining host tropism and pathogenesis.

SARS-CoV utilizes the host ACE2 receptor for binding to host cells, including numerous respiratory epithelial cell types, alveolar macrophages, and monocytes [27,48]. Multiple cell types lacking ACE2 expression are also permissive for SARS-CoV, suggesting that additional receptors or co-receptors exist for SARS-CoV and may contribute to infection $[49,50]$. MERS-CoV targets DPP4 (also known as CD26), which is broadly expressed on numerous epithelial cell types and activated leukocytes.

Figure 2. Phylogenetic analysis of the Spike (S) protein of 2019-nCoV with known coronavirus S proteins.

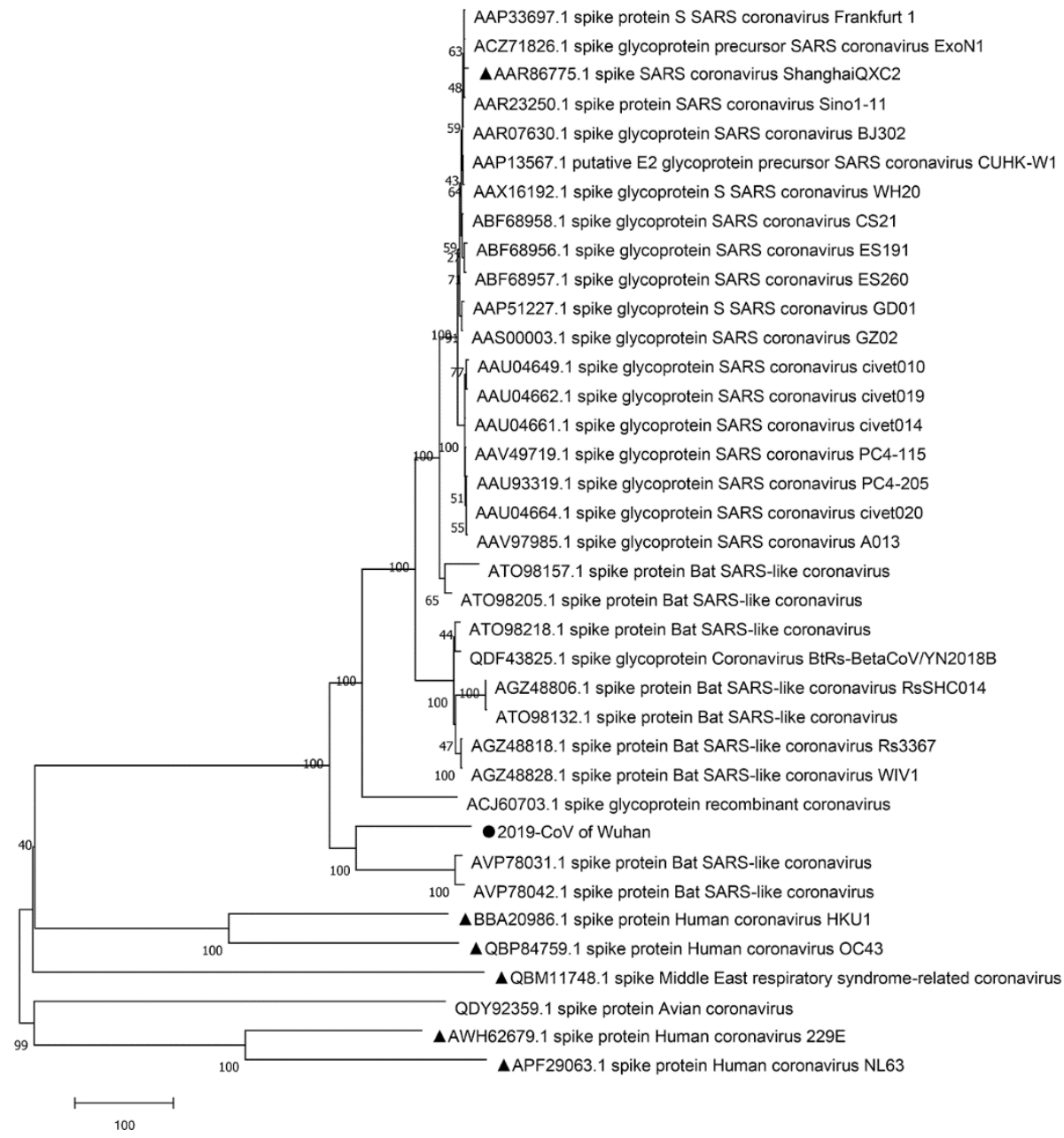

Phylogenetic analysis of the spike protein sequences of the $2019-\mathrm{nCoV}$ and some related coronaviruses. All the protein sequences used for the tree generation were downloaded from the National Center for Biotechnology Information (NCBI) and annotated by the accession number. Protein sequences were aligned using ClustalW. Then the tree was constructed with MEGA 7.0 by the neighbor-joining (NJ) method using 1,000 bootstraps. The Wuhan new coronavirus was marked by solid circle "•". SARS coronavirus Shanghai, Human coronavirus HKU1, Human coronavirus OC43, Middle East respiratory syndrome, Human coronavirus 229E and Human coronavirus NL63 were marked by solid triangle " $\mathbf{\Delta}$ ". The NJ tree was well-constructed; the Wuhan new coronavirus showed high identity with Bat SARS-like coronavirus and separated from other coronavirus into different clusters. 
Figure 3. Sequence comparison of the Spike (S) protein of 2019-nCoV to SARS-CoV and WIV-1 CoV.

A



Alignment of full-length S-protein from 2019-nCoV (QHD43416.1), SARS-CoV (P59594.1) and WIV1-CoV (AGZ48828.1). Red, yellow and white indicate completely conserved, functionally conserved and nonconserved residues respectively (A). 
DPP4 is widely expressed in various kidney cells and likely contributes to MERS-CoV infiltration and subsequent renal dysfunction [51,52]. DCs and macrophages can also be productively infected by MERS-CoV in vitro [44]. The 2019-nCoV receptor(s) is currently unknown. To better understand the possible relationship of the 2019-nCoV S protein to other coronaviruses, we generated a phylogenetic tree of $\mathrm{S}$ protein sequences from various human and animal coronaviruses (Figure 2). Our phylogenetic data shows that 2019-nCoV S most closely resembles the S protein from a SARS-like bat CoV followed by SARS-CoV and distantly resembles other human coronaviruses including the MERS-CoV S protein.

A more in-depth analysis of S-proteins from 2019nCoV, SARS-CoV, and WIV1-CoV, a SARS-like coronavirus that uses the ACE2 for cell entry, was conducted. An amino acid alignment of the S proteins (Figure 3A) shows high (92\%) similarity between SARS-CoV and WIV1-CoV S-proteins. Lower similarity $(77 \%)$ is observed between SARS-CoV and 2019-nCoV S-proteins. However, there may be sufficient conservation in the RBD (75\%) to expect that 2019-nCoV can still bind to ACE2. As a comparator, MERS-CoV S, which binds to a different receptor (dipeptidyl peptidase 4 ), has only $37 \%$ similarity to SARS-CoV S. Alignment of the RBD regions (Figure 3B) shows that 2019-nCoV has 6 amino acid substitutions in the 14 contact points between SARS$\mathrm{CoV} \mathrm{S}$ and ACE2 (Figure 3D). Three of these substitutions are also found in another group 2 coronavirus, WIV1-CoV, which has previously been shown to be capable of binding to human ACE2 in spite of these mutations [53].

To predict the binding affinity of $2019-\mathrm{nCoV}$ to human ACE2, structural models of SARS-CoV RBD, WIV1-CoV RBD and 2019-nCoV RBD were generated to allow for comparison of amino acid side chain positions and putative binding energies (Figure 4A). Pairwise structural comparisons of the generated models to the crystalized structure of the SARS-CoV RBD complexed to ACE2 yielded RMSD values of 1.2, 0.9 , and 0.9 for the SARS-CoV, WIV1-CoV, and 2019nCOV RBDs, respectively. The low RMSD value for

Figure 3. Sequence comparison of the Spike (S) protein of 2019-nCoV to SARS-CoV and WIV-1 CoV.

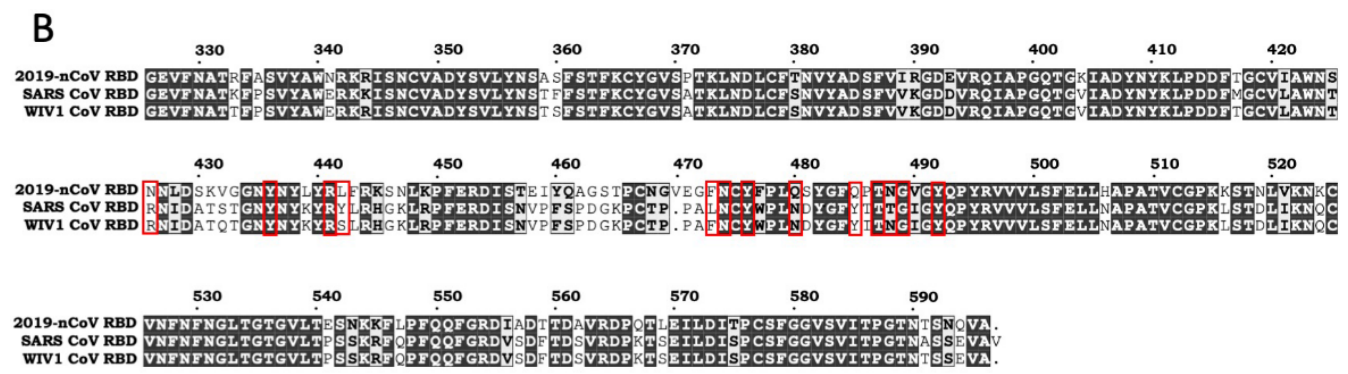

C

\begin{tabular}{|l|l|l|}
\hline S-protein & $2019-n C o V$ & SARS CoV \\
\hline SARS CoV & 77.30 & \\
\hline WIV1 CoV & 78.18 & 92.34 \\
\hline
\end{tabular}

\begin{tabular}{|l|l|l|}
\hline RBD & $2019-n C o V$ & SARS CoV \\
\hline SARS CoV & 74.81 & \\
\hline WIV1 CoV & 77.04 & 96.30 \\
\hline
\end{tabular}

D

\begin{tabular}{|c|c|c|c|c|c|c|c|c|c|c|c|c|c|c|}
\hline AA position & 402 & 426 & 436 & 441 & 442 & 472 & 473 & 475 & 479 & 484 & 486 & 487 & 488 & 491 \\
\hline SARS COV & $\mathrm{T}$ & $\mathrm{R}$ & $Y$ & $\mathrm{R}$ & $Y$ & $\mathrm{~L}$ & $\mathrm{~N}$ & $Y$ & $N$ & $Y$ & $\mathrm{~T}$ & $\mathrm{~T}$ & G & $Y$ \\
\hline WIV1 CoV & $\mathrm{T}$ & $\mathrm{R}$ & $Y$ & $\mathrm{R}$ & $\mathrm{S}$ & $\mathrm{F}$ & $\mathrm{N}$ & $Y$ & $\mathrm{~N}$ & $Y$ & $\mathrm{~T}$ & $\mathrm{~N}$ & G & $Y$ \\
\hline 2019-nCoV & $\mathrm{T}$ & $\mathrm{N}$ & $Y$ & $\mathrm{R}$ & $\mathrm{L}$ & $F$ & $\mathrm{~N}$ & $Y$ & $Q$ & $Q$ & $\mathrm{~T}$ & $N$ & G & $Y$ \\
\hline
\end{tabular}

Detailed alignment of the receptor binding domain (RBD) of nCoV-2019, SARS-CoV and WIV1-CoV (B). Black, grey and white indicate $100 \%$ conserved, functionally conserved, and nonconserved residues respectively. Red boxes indicate the S protein residues in the RBD that directly interact with the ACE2 receptor. Percent identity matrices for the full-length S-protein (left) and RBD (right) provided by ClustalW (C). Residues of the SARS-CoV RBD and the corresponding WIV1-CoV and 2019-nCoV amino acids that contact the human ACE2 receptor (D). Amino acid substitutions are shown in orange for WIV1 and in yellow for nCoV-2019 
the modelled SARS-CoV RBD supports the accuracy of the WIV1-CoV and 2019-nCoV RBD homology models. To observe the effects of the three additional mutations within the RBD of 2019-nCoV compared to WIV1-CoV at the binding interface (Figure 4B), the RBD models were structurally aligned to the crystal structure of the SARS-CoV RBD complexed to ACE2 [54]. The three residues mutated in RBD of WIV1-CoV - Asp487, Ser442, and Phe472 - were previously shown to have no effect on receptor binding affinity [53]. The remaining three mutations identified within the RBD of 2019-nCoV that interact with ACE2 residues have not been studied. The substitution of Arg426 to Asn426 removes the positively charged Rgroup of Arg but maintains the side chain's polarity and presence of an amide. Arg426 in the SARS-CoV RBD interacts with ACE2 residues Gln325 and Glu329. The structural model of 2019-nCoV RBD (Figure 4C) shows that the side chain of Gln426 is still in close proximity to ACE2 Gln325 and Glu329, suggesting that the substitution of Arg426 to Asn426 has little effect on receptor binding. Tyr484 to Gln484, introduces a polar amino acid within a region that includes several tyrosine residues. Within the SAR-CoV RBD, Tyr484 interacts with His34 of ACE2. The R-group of Gln should not inhibit receptor binding in this region, sterically or otherwise, when compared to the R-group of Tyr484. The third substitution unique to 2019-nCoV, Asn479 to Gln479, may induce a conformational change within the RBD due to its proximity to several tyrosines. However, a hydrogen bond is located in the area between RBD Gly488 and ACE2 Lys353 is conserved. This mutation is therefore unlikely to have any negative effect on ACE2 binding.

While the structure of the 2019-nCoV RBD appears to be well conserved, we wanted to determine whether the RBD/ACE2 interaction energies were comparable to the SARS-CoV RBD. Docking was carried out using

Figure 4. Receptor binding domain (RBD) structure predictions based on homology modelling by Phyre2.
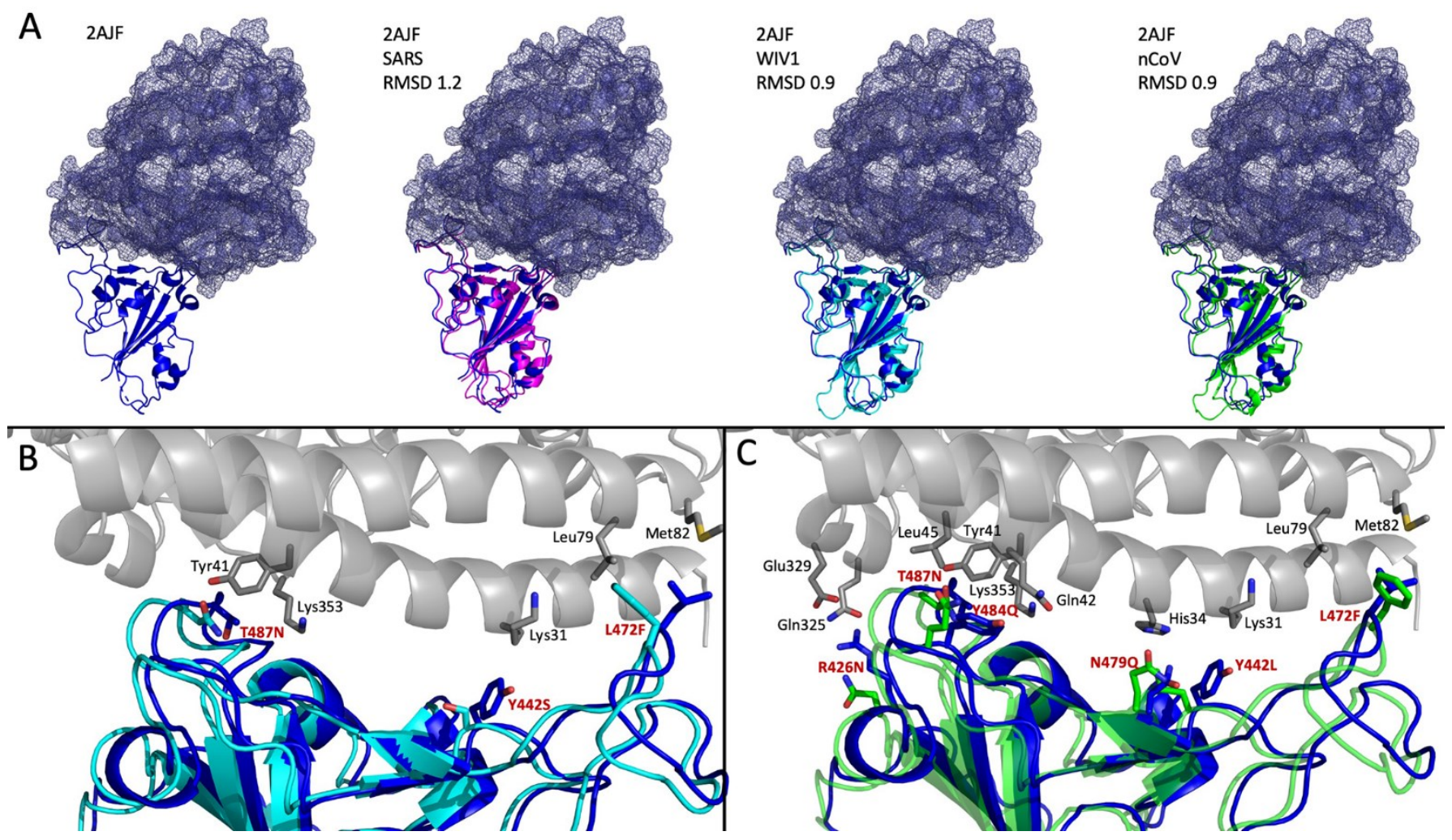

The crystal structure of the SARS-CoV RBD bound to ACE2 (PDB 2AJF), shown in dark blue, was used as a reference template for pairwise comparison with the Phyre2 models (A). Structural models generated by homology modelling for SARS-CoV RBD (magenta), WIV1-CoV RBD (cyan), and nCoV2019 RBD (green) are shown overlaid of 2AJF (blue). RMSD values for the structural comparison of the models to 2AJF were calculated by Dali-lite and are provided for each model. Binding interface of the SARS-CoV RBD (blue)/ACE2 (grey) crystal structure with the WIV1-CoV RBD model shown in cyan (B). ACE2 amino acids that interact with RBD residues are shown as grey sticks and the corresponding amino acids of the SARS-CoV RBD and the WIV1-CoV RBD homology model are shown in blue and cyan sticks, respectively, and have red labels detailing the WIV1 mutations. Binding interface of 2AJF SARS-CoV RBD (blue) and ACE2 (grey) overlaid with the 2019-nCoV homology model (green) (C). ACE2 interface residues are shown as grey sticks, and the SARS/2019-nCoV residues are shown in blue and green stick representation, respectively. The red labels for SARS/2019-nCoV residues detail the mutations present in the 2019-nCoV RBD homology model. 
the modelled RBDs and the pre-determined crystal structure of ACE2 (PDB ID: 2AJF, chain B) using HADDOCK2.2 [55]. The top models from the top cluster was selected for calculation of binding energy. The crystal structure of ACE2 complexed with SARSCoV RBD (PDB ID: 2AJF, chain B and E) was used as a positive binding control, while the crystal structure of SARS-CoV RBD (PDB ID: 2AJF, chain E) docked to rat ACE2 served as a negative binding control [56]. The binding energy of the crystallized ACE2/SARS-CoV complex was calculated as $-8.0 \mathrm{kcal} / \mathrm{mol}$, while the crystallized RBD structure docked to modeled rat ACE2 returned a binding energy of $-6.0 \mathrm{kcal} / \mathrm{mol}$ (Figure 5A). The $2.0 \mathrm{kcal} / \mathrm{mol}$ difference in binding energy would likely be larger if a crystal structure of SARS-RBD and rat ACE2 was used for comparison. The in silico docking strategy used here favours flexibility in the binding interface as opposed to the rigid nature of crystal structures. This effect is demonstrated with the modelled SARS-RBD and crystal ACE2 structures returning a binding energy of $12.5 \mathrm{kcal} / \mathrm{mol}$. Additionally, WIV1-CoV binds to
ACE2 for cell entry and the modelled WIV1$\mathrm{RBD} / \mathrm{ACE} 2$ returned a binding energy of -10.3 $\mathrm{kcal} / \mathrm{mol}$. A similar binding energy, $-10.2 \mathrm{kcal} / \mathrm{mol}$ was observed for the modelled RBD of 2019-nCoV and ACE2 suggesting that $2019-\mathrm{nCoV}$ is capable of binding to ACE2.

Three key residues within the RBD of SARS-CoV are associated with species-specific receptor recognition, Leu472, Asn479, and Thr487 [57]. All three of these residues are substituted in the 2019-nCoV RBD to Phe472, Gln479, and Asn487 respectively. The WIV1-CoV RBD contains Phe at position 472 and Asn at position 487 , but $\mathrm{G} \ln 479$ is unique to $2019-\mathrm{nCoV}$. As shown in Figure 5, the mutation in this region does not appear to have any effect on docking energies compared to WIV1 and is not predicted to have any negative effects on the ACE2 His34 residue it likely interacts with Leu472 to Phe472 also should have little to no effect on binding and may increase binding affinity due to the interacting ACE2 residue, Met82, since the methionine-aromatic interaction is considered to be a multifunctional motif that is involved in the

Figure 5. Binding energies of RBD homology models and their electrostatic surface potential.

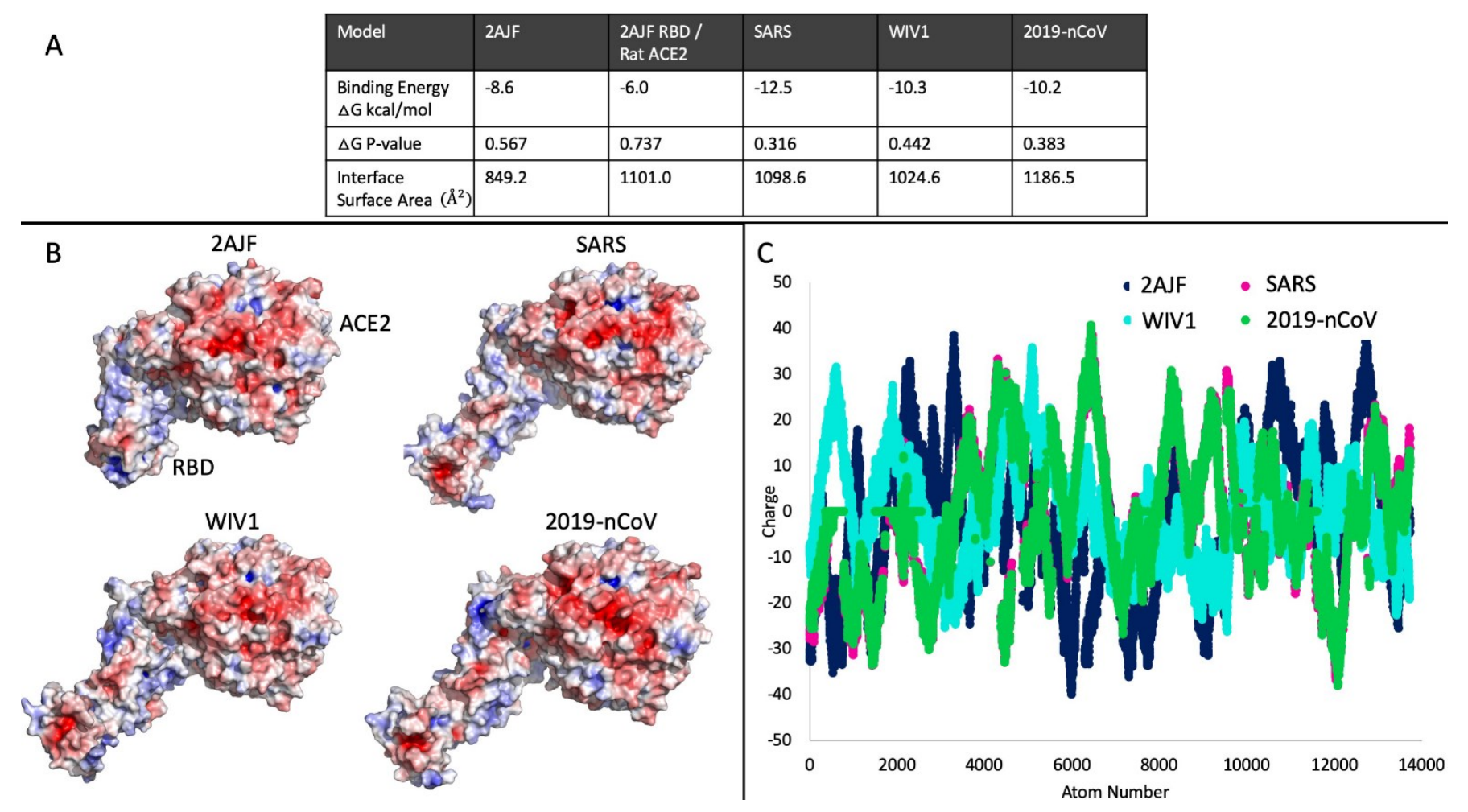

Table detailing the calculated binding energies for PDB ID 2AJF (chains B and E), the crystal structure of SARS-CoV RBD in complex with human ACE2, $2 \mathrm{AJF}$ chain E (SARS-CoV RBD) complexed with Rat ACE2, and the homology models complexed to ACE2 (2AJF, chain B) (A). The $\triangle \mathrm{G}$ P-values and interface surface areas are also provided. Electrostatic potential of 2AJF and the complexed models calculated with APBS (B). The ACE2 and RBD labels on $2 \mathrm{AJF}$ are the same for all models. Red indicates regions of net negative charge while blue indicates a net positive charge, and white is neutral. Graphical comparison of individual atom charges for $2 \mathrm{AJF}$ and the models showing the individual charges of each atom (C). 
stabilization of structures [58]. Thr487 to Gln487 does not inhibit binding as the substitution is also found in WIV1-CoV which can bind ACE2 for virus infection.

The electrostatic potentials of crystallized ACE2/SARS-CoV RBD and the RBD models were also determined (Figure 5C). Their atomic potential profiles are graphically represented and interestingly, 2019$\mathrm{nCoV}$ traces best with the potential of the SARS-CoV RBD homology model bound to ACE2. This could indicate that the $2019-\mathrm{nCoV}$ S-protein is more functionally similar to the SARS-CoV S-protein than initially anticipated from sequence similarities.

\section{Vaccines and Community Readiness}

Vaccine development

Vaccines provide protection from viral pathogens prior to exposure by eliciting protective immune memory with an innocuous agent. The development of neutralizing antibodies from a vaccine remains one of the hallmarks of effective vaccines although vaccines

Figure 6. Phylogenetic analysis of the envelope (E) protein sequence in novel 2019-nCoV.



All protein sequences used for tree generation were obtained from the National Center for Biotechnology Information (NCBI) and annotated by accession number. Protein sequences were then aligned using the ClustalW algorithm, and the tree was constructed with MEGA X by the neighbor-joining (NJ) method using 1,000 bootstraps. The solid black circle indicates the novel Wuhan pneumonia virus, and the solid black triangle indicates SARS coronavirus Shanghai and human coronaviruses HKU1, NL63, 229E, and OC43. The novel Wuhan coronavirus envelope protein shows high identity with Bat SARSlike coronavirus. 
that induce cell-mediated immunity have also shown potential and are in development for viral pathogens such as influenza viruses. Several vaccine platforms exist with the ability to induce protective responses: killed whole virus vaccines; split-virion vaccines; subunit vaccines; live-attenuated viral vaccines; viruslike particle vaccines; nanoparticle vaccines; and nucleic acid vaccines (DNA and RNA). In regard to choosing a vaccine target and platform, the vaccine candidate must be immunogenic and immune targeting must lead to virus neutralization or potent cytotoxic responses. To date, there is not a licenced vaccine for either SARS-CoV or MERS-CoV although clinical trials have been initiated for MERS-CoV vaccines. Much of the focus for the development of a SARS-CoV or MERS-CoV vaccine has been on the S protein since it is immunogenic and antibodies targeting it can neutralize the virus $[59,60]$. Our analysis of the $\mathrm{S}$ protein (Figure 2) suggests that it has potential for vaccine development which can be related to work previously done for SARS-CoV and MERS-CoV.

The envelope protein (E) is also an attractive vaccine target that has been proposed for leverage in the development of live-attenuated vaccines $[60,61]$. MERS-CoV mutants with the E protein deleted are replication-competent but propagation-defective [61]. Similar results were shown for the SARS-CoV when E was removed [62]. Together this suggests that deletion of $\mathrm{E}$ from coronaviruses may provide a safe-single replication live viral vaccine for use in inducing a mucosal immune response. We investigated the similarity of the $\mathrm{E}$ protein of $2019-\mathrm{nCoV}$ by phylogenetic analysis against known coronavirus $\mathrm{E}$ protein sequences (Figure 6) and found clustering, although somewhat distant, with human SARS-CoV. Given that vaccines have been generated for MERSand SARS-CoVs by mutating the E protein, an E-based vaccine may represent an alternate candidate for 2019$\mathrm{nCoV}$ vaccines. As vaccine candidates are identified, the requirement of animal models for vaccine development and evaluation will be essential.

\section{Animal model development}

Establishing an animal model of infection and disease pathogenesis is imperative for understanding several essential elements of viral disease in the infected host, including host tropism, immune responses, and modes of transmission, as well as for the progression of therapeutic development. Having an animal model that can recapitulate human disease is essential for vaccine and therapeutic development as well as testing. For a potential animal model to be susceptible to infection, the virus must be able to 1.) gain entry into host cells; 2.) overcome the host's antiviral responses; and 3.) disseminate virus following infection to allow infection of other neighbouring cells and tissues. It is also of importance for the model to be able to recapitulate human disease and viral transmission modes. When evaluating the ability of an animal to be infected by a virus and serve as a model, viral shedding, clinical disease, and seroconversion should be determined. The past animal models for SARS-CoV and MERS-CoV were not universal due to the expression of the virus-specific cellular receptors for entry [63]. As SARS-CoV and MERS-CoV do not share a cellular receptor, they do not share the same host range and susceptibility, which includes research animal models [64]. Cynomolgus macaques, ferrets, and cats were some of the first animals to be determined susceptible to SARS-CoV $[65,66]$. The advantage of ferrets is that they are a smaller animal compared to non-human primates and also are able to recapitulate some of the clinical symptoms and transmission kinetics of human respiratory viruses including coughing, sneezing, fever, and weight loss [67]. Although mice can be infected with SARS-CoV, as shown by recovery of vRNA and the elicitation of neutralizing antibodies, infection does not cause severe disease[68]. However, SARS-CoV could be passaged in mice (15 times) for the establishment of a model with clinical features[69]. After the identification of MERS$\mathrm{CoV}$, it was quickly determined that typical research animal models were not susceptible to the virus including mice, Syrian hamsters, and ferrets. Larger non-human primate models, such as Rhesus macaques and common marmoset were determined susceptible. To make use of small animal models, transgenic mice have been engineered for MERS-CoV susceptibility through expression of the human DPP4 receptor [70]. Other attempts at other mouse model developments were not successful, including an immunocompromised 129/SATA1-/-1 mouse [63]. Having an understanding of the animal models and model development previously utilized for the other coronaviruses of interest will aid in the development of a model for 2019$\mathrm{nCoV}$. As is necessary, elucidation of the receptor will help guide in development, and creating a clinical picture of the acute symptoms in humans will be essential for vaccine and antiviral evaluation.

\section{Community Readiness}

Community and healthcare preparedness in response to coronavirus outbreaks remain ongoing obstacles for global public health. For example, delays 
between disease development and progression and diagnosis or quarantine can severely impact both patient management and containment [21,71]. Deficiencies in outbreak preparedness and healthcare network coordination efforts must ultimately be considered in response efforts. It is strongly recommended that universal reagents be maintained and available at global repositories for future outbreaks.

\section{Future Directions}

At the time of this writing, cases continue to be reported. Furthermore, there are also many unknowns regarding this outbreak, including the reservoir host, modes of transmission/transmission potential, and the effectiveness of potential vaccine candidates. Here we have attempted to address some of these issues using foundations from previous coronavirus outbreaks as well as our own analysis. What is certain is that the numbers of reported cases are increasing and will continue to increase before the knowledge gaps surrounding 2019-nCoV are filled. Cooperation among public health officials, healthcare workers, and scientists will be key to gaining a foothold and containing virus spread. Acknowledgement of coronaviruses as a constant spillover threat is important for pandemic preparedness. Two key take-away messages are important at this time: 1) As noted by the previous lopsided cases of healthcare, healthcare workers and care givers should exercise extreme caution and use personal protective equipment (PPE) in providing care to 2019-nCoV infected patients; and 2) The research community should endeavour to compile diverse $\mathrm{CoV}$ reagents that can quickly be mobilized for rapid vaccine development, antiviral discovery, differential diagnosis, and specific diagnosis.

\section{Methods}

\section{Phylogenetic Tree Analysis}

The nucleotide sequence of the novel coronavirus associated with the outbreak of pneumonia in Wuhan (2019-nCoV) was downloaded from the National Center for Biotechnology Information (NCBI) (http://www.ncbi.nlm.nih.gov) with the accession number MN908947.3 [72]. The encoded S proteins and E proteins from additional coronaviruses were selected for the construction of a neighbor-joining tree. All sequences were downloaded from NCBI, and the accession numbers were annotated in the NJ tree. Protein sequences were aligned using ClustalW [73] and then used to construct the tree with MEGA7.0 [74] using 1,000 bootstraps.
Receptor Binding Domain (RBD) Alignment, Predictions, and Modeling

Amino acid sequences for the $\mathrm{S}$ protein of SARSCoV (P59594.1), WIV1-CoV (AGZ48828.1), and 2019-nCoV (QHD43416.1), were obtained from GenBank. Alignments were completed using ClustalW with default parameters and the output was formatted with Espript $[75,76]$. The $\mathrm{S}$ protein sequences were submitted to Phyre2 for homology modelling under 'Intensive' mode and the subsequent structures were further refined using 3D refined for energy minimization [77,78]. The refined model with the lowest RMSD value was selected for use in structural comparisons and docking. The RBD models were compared to the crystal structure of SARS-CoV RBD (PDB ID:2AJF, chain E) using DaliLite v.5 pairwise comparison tool for analysis [79]. The RBD models were submitted for docking analysis to human ACE2 (PDB ID: 2AJF, chain B) using HADDOCK 2.2 [55] with residues $24,27,31,34,37,38,41,42,45,79,82$, $83,90,325,329,330,353$, and 354 of ACE2 specified as a binding domain as well as RBD residues 402, 426, 436, 441, 442, 472, 473, 475, 479, 484, 486, 487, 488, and 491 [55]. The complex with the lowest z-score was selected and the binding energy was calculated using the PDBePISA server [80]. Electrostatics of the complexes were also determined using adaptive Poisson-Boltzmann solver (APBS) calculations and PyMol to show surface electrostatics for the docked RBD models and 2AJF [81,82]. Individual atom charges of each model and 2AJF were used for comparison of electrostatic potential between 2AJF and the models.

\section{Acknowledgements and Funding}

Research into the novel coronavirus genome (2019-nCoV) was led by Dr. Yong-Zhen Zhang at the the Shanghai Public Health Clinical Center \& School of Public Health, in collaboration with the Central Hospital of Wuhan, Huazhong University of Science and Technology, the Wuhan Center for Disease Control and Prevention, the National Institute for Communicable Disease Control and Prevention, the Chinese Center for Disease Control, and the University of Sydney, Sydney, Australia. We would like to thank and acknowledge the researchers who were working to identify this pathogen and make the data publically available. Specifically, we acknowledge the National Institute for Viral Disease Control and Prevention, China CDC; Wuhan Institute of Virology, Chinese Academy of Sciences; Institute of Pathogen Biology, Chinese Academy of Medical Sciences \& Peking Union Medical College; and Wuhan Jinyintan Hospital. In addition, we acknowledge GISAID (https://www.gisaid.org/) for providing a platform that allows data to be freely shared. J.K. 
is funded by a Tier 2 Canada Research Chair in the Molecular Pathogenesis of Emerging and Re-Emerging Viruses provided by the Canadian Institutes of Health Research (Grant no. 950-231498). A.A.K. is funded by the IWK Health Centre (Grant no. 602975) and Nova Scotia Health Research Foundation (Grant no. 602932). DJK is a Tier 1 Canada Research Chair in Translational Vaccinology and Inflammation. Support for DJK was provided by LKSF, Canada Foundation for Innovation (JELF), and DMRF (Dalhousie Medical Research Foundation). VIDO-InterVac receives operational funding from the Government of Canada through Canada Foundation for Innovation - Major Science Initiatives and the Government of Saskatchewan through Innovation Saskatchewan. D.F. receives support from Canadian Institutes for Health Research (PJT 388665).

\section{References}

1. China, TSCIOotPsRo. Press Conference on Pneumonia Prevention and Control of the New Coronavirus Infection held 10 am Beijing time. Available from: https://www.scio.gov.cn/xwfbh/xwbfbh/wqfbh/42311/42470/i ndex.htm.

2. ProMed International Soceity for Infectious Diseases, PISfI, ProMed 20191230.6864153 Undiagnosed Pneumonia - China (Hubei): Request for Information. 2019.

3. Diseases, P.I.S.f.I. 20200102.6866757 Undiagnosed Pneumonia - China (Hubei) (01): Wildlife sales, market closed, Request for Information. 2020.

4. Diseases, P.I.S.f.I. 20200103.6869668 Undiagnosed Pneumonia - China (Hubei) (02): Updates, other countries responses, Request for Information. 2020.

5. Diseases, P.I.S.f.I. 20200105.6872267 Undiagnosed Pneumonia - China (Hubei) (03): Updates, severe acute respiratory syndrome, Middle East Respiratory Syndrome rouled rouled out, WHO, Request for Information. 2020.

6. Diseases, P.I.S.f.I. 20200108.6877694 Undiagnosed Pneumonia - China (Hubei) (05): Novel Coronavirus identified. 2020.

7. Diseases, P.I.S.f.I. 20200108.6878869 Undiagnosed Pneumonia - China (HU) (07): official confirmation of novel coronavirus. 2020.

8. Diseases, P.I.S.f.I. 20200110.6881082 Undiagnosed Pneumonia - China (Hubei) (08): Novel Coronavirus, WHO. 2020.

9. Diseases, P.I.S.f.I. 20200110.6883253 Undiagnosed Pneumonia - China (Hubei) (09): Novel Coronavirus, more iformation, first fatality. 2020.

10. Diseases, P.I.S.f.I. 20200113.6886644 Novel Coronavirus (02): Thailand ex China (Hubei) WHO. 2020.

11. Diseases, P.I.S.f.I. 20200114.6889527 Novel Coronavirus (04): China (Hubei), Thailand ex China, WHO. 2020.

12. Diseases, P.I.S.f.I. 20200115.6891515 Novel Coronavirus (05): China (HU), Japan ex China. 2020.

13. Diseases, P.I.S.f.I. 20200120.6899007 Novel Coronavirus (11) - China (Hubei) South Korea ex China. 2020.

14. Diseases, P.I.S.f.I. 20200121.6901757 Novel Coronavirus (12): China (Hubei) New fatality, healthcare workers, WHO. 2020.

15. World Health Organization (WHO) (2020) Diagnostics for novel coronavirus. Available: https:/www.who.int/healthtopics/coronavirus/laboratory-diagnostics-for-novelcoronavirus. Accessed : 23 January 2020.
16. Canducci F, Debiaggi M, Sampaolo M, Marinozzi MC, Berre S, Terulla C, Gargantini G, Cambieri P, Romero E, Clementi M (2008) Two-year prospective study of single infections and co-infections by respiratory syncytial virus and viruses identified recently in infants with acute respiratory disease. J Med Virol 80: 716-723.

17. Jevsnik M, Ursic T, Zigon N, Lusa L, Krivec U, Petrovec M (2012) Coronavirus infections in hospitalized pediatric patients with acute respiratory tract disease. BMC Infect Dis 12: 365.

18. Fehr AR, Perlman S (2015) Coronaviruses: an overview of their replication and pathogenesis. Methods Mol Biol 1282: 123.

19. Donnelly CA, Ghani AC, Leung GM, Hedley AJ, Fraser C, Riley S, Abu-Raddad JL, Ho LM, Thach TQ, Chau P, Chan KP, Lam TH, Tse LY, Tsang T, Liu SH, Kong JH, Lau EM, Ferguson NM, Anderson RM (2003) Epidemiological determinants of spread of causal agent of severe acute respiratory syndrome in Hong Kong. Lancet 361: 1761-1766.

20. de Wit E, van Doremalen N, Falzarano D, Munster VJ (2016) SARS and MERS: recent insights into emerging coronaviruses. Nat Rev Microbiol 14: 523-534.

21. Walston S, Al-Harbi Y, Al-Omar B (2008) The changing face of healthcare in Saudi Arabia. Ann Saudi Med 28: 243-250.

22. AL-Ahmadi H, Roland M (2005) Quality of primary health care in Saudi Arabia: a comprehensive review. Int J Qual Health Care 17: 331-346.

23. Assiri A, Al-Tawfiq JA, Al-Rabeeah AA, Al-Rabiah FA, AlHajjar S, Al-Barrak A, Flemban H, Al-Nassir WN, Balkhy HH, Al-Hakeem RF, Makhdoom HQ, Zumla AI, Memish ZA (2013) Epidemiological, demographic, and clinical characteristics of 47 cases of Middle East respiratory syndrome coronavirus disease from Saudi Arabia: a descriptive study. Lancet Infect Dis 13: 752-761.

24. Hunter JC, Nguyen D, Aden B, Al Bandar Z, Al Dhaheri W, Abu Elkheir K, Khudair A, Al Mulla M, El Saleh F, Imambaccus H, Al Kaabi N, Sheikh FA, Sasse J, Turner A, Abdel Wareth L, Weber S, Al Ameri A, Abu Amer W, Alami NN, Bunga S, Haynes LM, Hall AJ, Kallen AJ, Kuhar D, Pham H, Pringle K, Tong S, Whitaker BL, Gerber SI, Al Hosani FI (2016) Transmission of Middle East Respiratory Syndrome Coronavirus infections in healthcare settings, Abu Dhabi. Emerg Infect Dis 22: 647-656.

25. Arabi YM, Arifi AA, Balkhy HH, Najm H, Aldawood AS, Ghabashi A, Hawa H, Alothman A, Khaldi A, Al Raiy B (2014) Clinical course and outcomes of critically ill patients with Middle East respiratory syndrome coronavirus infection. Ann Intern Med 160: 389-397.

26. Guery B, Poissy J, el Mansouf L, Sejourne C, Ettahar N, Lemaire X, Vuotto F, Goffard A, Behillil S, Enouf V, Caro V, Mailles A, Che D, Manuguerra JC, Mathieu D, Fontanet A, van der Werf A, ME-Cs group (2013) Clinical features and viral diagnosis of two cases of infection with Middle East Respiratory Syndrome coronavirus: a report of nosocomial transmission. Lancet 381: 2265-2272.

27. Memish ZA, Zumla AI, Al-Hakeem RF, Al-Rabeeah AA, Stephens GM (2013) Family cluster of Middle East respiratory syndrome coronavirus infections. N Engl J Med 368: 24872494.

28. Zaki AM, van Boheemen S, Bestebroer TM, Osterhaus AD, Fouchier RA (2012) Isolation of a novel coronavirus from a man with pneumonia in Saudi Arabia. N Engl J Med 367: 18141820.

29. Al-Tawfiq JA, Hinedi K, Ghandour J, Khairalla H, Musleh S, Ujayli A, Memish ZA (2014) Middle East respiratory 
syndrome coronavirus: a case-control study of hospitalized patients. Clin Infect Dis 59: 160-165.

30. Ajlan AM, Ahyad RA, Jamjoom LG, Alharthy A, Madani TA (2014) Middle East Respiratory Syndrome Coronavirus (MERS-CoV) infection: chest CT findings. AJR Am J Roentgenol 203: 782-787.

31. Zumla A, Hui DS, Perlman S (2015) Middle East respiratory syndrome. Lancet 386: 995-1007.

32. Chan JF, Lau SK, To KK, Cheng VC, Woo PC, Yuen KY (2015) Middle East respiratory syndrome coronavirus: another zoonotic betacoronavirus causing SARS-like disease. Clin Microbiol Rev 28: 465-522.

33. Albarrak AM, Stephens GM, Hewson R, Memish ZA (2012) Recovery from severe novel coronavirus infection. Saudi Med J 33: 1265-1269.

34. Omrani AS, Saad MM, Baig K, Bahloul A, Abdul-Matin M, Alaidaroos AY, Almakhlafi GA, Albarrak MM, Memish ZA, Albarrak AM (2014) Ribavirin and interferon alfa-2a for severe Middle East respiratory syndrome coronavirus infection: a retrospective cohort study. Lancet Infect Dis 14: 1090-1095.

35. Chan JF, Yao Y, Yeung ML, Deng W, Bao L, Jia L, Li F, Xiao C, Gao H, Yu P, Cai JP, Chu H, Zhou J, Chen H, Qin C, Yuen KY (2015) Treatment with lopinavir/ritonavir or interferonbeta1b improves outcome of MERS-CoV infection in a Nonhuman primate model of common marmoset. J Infect Dis 212: 1904-1913.

36. Hart BJ, Dyall J, Postnikova E, Zhou H, Kindrachuk J, Johnson RF, Olinger GG Jr., Frieman MB, Holbrook MR, Jahrling PB, Hensley L (2014) Interferon-beta and mycophenolic acid are potent inhibitors of Middle East respiratory syndrome coronavirus in cell-based assays. J Gen Virol 95: 571-577.

37. Chan JF, Chan KH, Kao RY, To KK, Zheng BJ, Li CP, Li PT, Dai J, Mok FK, Chen H, Hayden FG, Yuen KY (2013) Broadspectrum antivirals for the emerging Middle East respiratory syndrome coronavirus. J Infect 67: 606-616.

38. Arabi YM, Alothman A, Balkhy HH, Al-Dawood A, AlJohani S, Al Harbi S, Kojan S, Al Jeraisy M, Deeb AM, Assiri AM, Al-Hameed F, AlSaedi A, Mandourah Y, Almekhlafi GA, Sherbeeni NM, Elzein FE, Memon J, Taha Y, Almotairi A, Maghrabi KA, Qushmaq I, Al Bshabshe A, Kharaba A, Shalhoub S, Jose J, Fowler RA, Hayden FG, Hussein MA, Mtg And the (2018) Treatment of Middle East Respiratory Syndrome with a combination of lopinavir-ritonavir and interferon-beta1b (MIRACLE trial): study protocol for a randomized controlled trial. Trials 19: 81 .

39. Chan PK, Chan MC (2013) Tracing the SARS-coronavirus. J Thorac Dis 5 Suppl 2: 118-121.

40. Song HD, Tu CC, Zhang GW, Wang SY, Zheng K, Lei LC, Chen QX, Gao YW, Zhou HQ, Xiang H, Zheng HJ, Chern SW, Cheng F, Pan CM, Xuan H, Chen SJ, Luo HM, Zhou DH, Liu YF, He JF, Qin PZ, Li LH, Ren YQ, Liang WJ, Yu YS, Anderson L, Wang M, Xu RH, Wu XW, Zheng HY, Chen JD, Liang G, Gao Y, Liao M, Fang L, Jiang LY, Li H, Chen F, Di B, He LJ, Lin JY, Tong S, Kong X, Du L, Hao P, Tang H, Bernini A, Yu XJ, Spiga O, Guo ZM, Pan HY, He WZ, Manuguerra JC, Fontanet A, Danchin A, Niccolai N, Li YX, Wu CI, Zhao GP (2005) Cross-host evolution of severe acute respiratory syndrome coronavirus in palm civet and human. Proc Natl Acad Sci USA 102: 2430-1435.

41. Shi Z, Hu Z (2008) A review of studies on animal reservoirs of the SARS coronavirus. Virus Res 133: 74-87.

42. Memish ZA, Cotton M, Meyer B, Watson SJ, Alsahafi AJ, Al Rabeeah AA, Corman VM, Sieberg A, Makhdoom HQ, Assiri A, Al Masri M, Aldabbagh S, Bosch BJ, Beer M, Muller MA,
Kellam P, Drosten C (2014) Human infection with MERS coronavirus after exposure to infected camels, Saudi Arabia, 2013. Emerg Infect Dis 20: 1012-1015.

43. Alagaili AN, Briese T, Mishra N, Kapoor V, Sameroff SC, Burbelo PD, de Wit E, Munster VJ, Hensley LE, Zalmout IS, Kapoor A, Epstein JH, Karesh WB, Daszak P, Mohammed OB, Lipkin WI (2014) Middle East respiratory syndrome coronavirus infection in dromedary camels in Saudi Arabia. mBio 5: e00884-14.

44. Willman M, Kobasa D, Kindrachuk J (2019) A Comparative analysis of factors influencing two outbreaks of Middle Eastern Respiratory Syndrome (MERS) in Saudi Arabia and South Korea. Viruses 11: 11. pii: E1119.

45. Anderson RM, Fraser C, Ghani AC, Donnelly CA, Riley S, Ferguson NM, Leung GM, Lam TH, Hedley AJ (2004) Epidemiology, transmission dynamics and control of SARS: the 2002-2003 epidemic. Philos Trans R Soc Lond B Biol Sci 359: 1091-1105.

46. Cowling BJ, Park M, Fang VJ, Wu P, Leung GM, Wu JT (2015) Preliminary epidemiological assessment of MERSCoV outbreak in South Korea, May to June 2015. Euro Surveill 20: 7-13.

47. Li F (2016) Structure, function, and evolution of coronavirus spike proteins. Annu Rev Virol 3: 237-261.

48. Qiu W, Chu C, Mao A, Wu J (2018) The impacts on health, society, and economy of SARS and H7N9 outbreaks in China: A case comparison study. J Environ Public Health 2018: 2710185.

49. Gu J, Gong E, Zhang B, Zheng J, Gao Z, Zhong Y, Zou W, Zhan J, Wang S, Xie Z, Zhuang H, Wu B, Zhong H, Shao H, Fang W, Gao D, Pei F, Li X, He Z, Xu D, Shi X, Anderson VM, Leong AS (2005) Multiple organ infection and the pathogenesis of SARS. J Exp Med 202: 415-424.

50. Hamming I, Timens W, Bulthuis ML, Lely AT, Navis G, van Goor H (2004) Tissue distribution of ACE2 protein, the functional receptor for SARS coronavirus. A first step in understanding SARS pathogenesis. J Pathol 203: 631-637.

51. Lambeir AM, Durinx C, Scharpe S, De Meester I (2003) Dipeptidyl-peptidase IV from bench to bedside: an update on structural properties, functions, and clinical aspects of the enzyme DPP IV. Crit Rev Clin Lab Sci 40: 209-294.

52. Widagdo W, Raj VS, Schipper D, Kolijn K, van Leenders G, Bosch BJ, Bensaid A, Segales J, Baumgartner W, Osterhaus A, Koopmans MP, van den Brand JMA, Haagmans BL (2016) Differential expression of the Middle East Respiratory Syndrome Coronavirus receptor in the upper respiratory tracts of humans and dromedary camels. J Virol 90: 4838-4842.

53. Menachery VD, Yount Jr. BL, Sims AC, Debbink K, Agnihothram SS, Gralinski LE, Graham RL, Scobey T, Plante JA, Royal SR, Swanstrom J, Sheahan TP, Pickles RJ, Corti D, Randell SH, Lanzavecchia A, Marasco WA, Baric RS (2016) SARS-like WIV1-CoV poised for human emergence. Proc Natl Acad Sci USA 113: 3048-3053.

54. Li W, Zhang C, Sui J, Kuhn JH, Moore MJ, Luo S, Wong SK, Huang IC, Xu K, Vasilieva N, Murakami A, He Y, Marasco WA, Guan Y, Choe H, Farzan M (2005) Receptor and viral determinants of SARS-coronavirus adaptation to human ACE2. EMBO J 24: 1634-1643.

55. van Zundert GCP, Rodrigues J, Trellet M, Schmitz C, Kastritis PL, Karaca E, Melquiond ASJ, van Dijk M, de Vries SJ, Bonvin A (2016) The HADDOCK2.2 Web server: Userfriendly integrative modeling of biomolecular complexes. J Mol Biol 428: 720-725.

56. Li W, Greenough TC, Moore MJ, Vasilieva N, Somasundaran M, Sullivan JL, Farzan M, Choe H (2004) Efficient replication 
of severe acute respiratory syndrome coronavirus in mouse cells is limited by murine angiotensin-converting enzyme 2 . J Virol 78: 11429-114233.

57. Li F, Li W, Farzan M, Harrison SC (2005) Structure of SARS coronavirus spike receptor-binding domain complexed with receptor. Science 309: 1864-1868.

58. Weber DS, Warren JJ (2019) The interaction between methionine and two aromatic amino acids is an abundant and multifunctional motif in proteins. Arch Biochem Biophys 672: 108053.

59. Agnihothram S, Gopal R, Yount BL Jr, Donaldson EF, Menachery VD, Graham RL, Scobey TD, Gralinski LE, Denison MR, Zambon M, Baric RS (2014) Evaluation of serologic and antigenic relationships between middle eastern respiratory syndrome coronavirus and other coronaviruses to develop vaccine platforms for the rapid response to emerging coronaviruses. J Infect Dis 209: 995-1006.

60. Yong CY, Ong HK, Yeap SK, Ho KL, Tan WS (2019) Recent Advances in the Vaccine Development Against Middle East Respiratory Syndrome-Coronavirus. Front Microbiol 10: 1781.

61. Almazan F, DeDiego ML, Sola I, Zuniga S, Nieto-Torres JL, Marquez-Jurado S, Andres G, Enjuanes L (2013) Engineering a replication-competent, propagation-defective Middle East respiratory syndrome coronavirus as a vaccine candidate. $\mathrm{mBio}$ 4: e00650-13.

62. DeDiego ML, Alvarez E, Almazan F, Rejas MT, Lamirande E, Roberts A, Shieh WJ, Zaki SR, Subbarao K, Enjuanes L (2007) A severe acute respiratory syndrome coronavirus that lacks the E gene is attenuated in vitro and in vivo. J Virol 81: 1701-1713.

63. van Doremalen N, Munster VJ (2015) Animal models of Middle East respiratory syndrome coronavirus infection. Antiviral Res 122: 28-38.

64. Li F (2015) Receptor recognition mechanisms of coronaviruses: a decade of structural studies. J Virol 89: 19541964.

65. Kuiken T, Fouchier RA, Schutten M, Rimmelzwaan GF, van Amerongen G, van Riel D, Laman JD, de Jong T, van Doornum G, Lim W, Ling AE, Chan PK, Tam JS, Zambon MC, Gopal $\mathrm{R}$, Drosten C, van der Werf S, Escriou N, Manuguerra JC, Stohr K, Peiris JS, Osterhaus AD (2003) Newly discovered coronavirus as the primary cause of severe acute respiratory syndrome. Lancet 362: 263-270.

66. Martina BE, Haagmans BL, Kuiken T, Fouchier RA, Rimmelzwaan GF, Van Amerongen G, Peiris JS, Lim W, Osterhaus AD (2003) Virology: SARS virus infection of cats and ferrets. Nature 425: 915.

67. Banner D, Kelvin AA (2012) The current state of H5N1 vaccines and the use of the ferret model for influenza therapeutic and prophylactic development. J Infect Dev Ctries 6: 465-9.

68. Wentworth DE, Gillim-Ross L, Espina N, Bernard KA (2004) Mice susceptible to SARS coronavirus. Emerg Infect Dis 10: 1293-1296.

69. Roberts A, Deming D, Paddock CD, Cheng A, Yount B, Vogel L, Herman BD, Sheahan T, Heise M, Genrich GL, Zaki SR, Baric R, Subbarao K (2007) A mouse-adapted SARScoronavirus causes disease and mortality in BALB/c mice. PLoS Pathog 3: e5.

70. Agrawal AS, Garron T, Tao X, Peng BH, Wakamiya M, Chan TS, Couch RB, Tseng CT, (2015) Generation of a transgenic mouse model of Middle East respiratory syndrome coronavirus infection and disease. J Virol 89: 3659-3670.

71. Al-Ahmadi, Roland M (2005) Quality of primary health care in Saudi Arabia: a comprehensive review. Int J Qual Health Care 17: 331-346.

72. Wu F, Zhao S, Yu B, Chen YM, Wang W, Hu Y, Song ZG, Tao ZW, Tian JH, Pei YY, Yuan ML, Zhang YL, Dai FH, Liu Y, Wang QM, Zheng JJ, Xu L, Holmes EC, Zhang YZ (2020) A novel coronavirus associated with a respiratory disease in Wuhan of Hubei province, China. NCBI.

73. Larkin MA, Blackshields G, Brown NP, Chenna R, McGettigan PA, McWilliam H, Valentin F, Wallace IM, Wilm A, Lopez R, Thompson JD, Gibson TJ, Higgins DG (2007) Clustal W and Clustal X version 2.0. Bioinformatics 23: 29472948.

74. Kumar S, Stecher G, Tamura K (2016) MEGA7: Molecular evolutionary genetics analysis version 7.0 for bigger datasets. Mol Biol Evol 33: 1870-1874

75. Sievers F, Wilm A, Dineen D, Gibson TJ, Karplus K, Li W, Lopez R, McWilliam H, Remmert M, Soding J, Thompson JD, Higgins DG (2011) Fast, scalable generation of high-quality protein multiple sequence alignments using Clustal Omega. Mol Syst Biol 7: 539.

76. Robert X, Gouet P (2014) Deciphering key features in protein structures with the new ENDscript server. Nucleic Acids Res 42: 320-324.

77. Kelley LA, Mezulis S, Yates CM, Wass MN, Sternberg MJ (2015) The Phyre2 web portal for protein modeling, prediction and analysis. Nat Protoc 10: 845-858.

78. Bhattacharya D, Nowotny J, Cao R, Cheng J (2016) 3Drefine: an interactive web server for efficient protein structure refinement. Nucleic Acids Res 44: 406-409.

79. Holm L (2019) Benchmarking fold detection by DaliLite v.5. Bioinformatics 35: 5326-5327.

80. Krissinel E, Henrick K (2007) Inference of macromolecular assemblies from crystalline state. J Mol Biol 372: 774-797.

81. Jurrus E, Engel D, Star K, Monson K, Brandi J, Felberg LE, Brookes DH, Wilson L, Chen J, Liles K, Chun M, Li P, Gohara DW, Dolinsky T, Konecny R, Koes DR, Nielsen JE, HeadGordon T, Geng W, Krasny R, Wei GW, Holst MJ, McCammon JA, Baker NA (2018) Improvements to the APBS biomolecular solvation software suite. Protein Sci 27: 112-128.

82. Schrodinger, LLC. The PyMOL Molecular Graphics System, Version 2.1.1.

\section{Corresponding author}

Alyson Kelvin, PhD

Assistant Professor

Faculty of Medicine - Department of Pediatrics - Dalhousie

University

IWK Health Centre \& Canadian Centre for Vaccinology

5980 University Ave, 4th Floor, R4020

Halifax, NS. B3K 6R8 Canada

Phone: (902) 470-2760

Fax: (902) 494-5125

akelvin@dal.ca

Conflict of interests: No conflict of interests is declared. 


\section{Annex - Supplementary Items}

Figure S1. Interaction of RBD residues involved in species specificity and ACE2. The RBD homology models docked to ACE2 are shown with emphasis placed on three residues associated with SARS-CoV species specificity: Leu472, Asn479, and Thr487.

Leu472

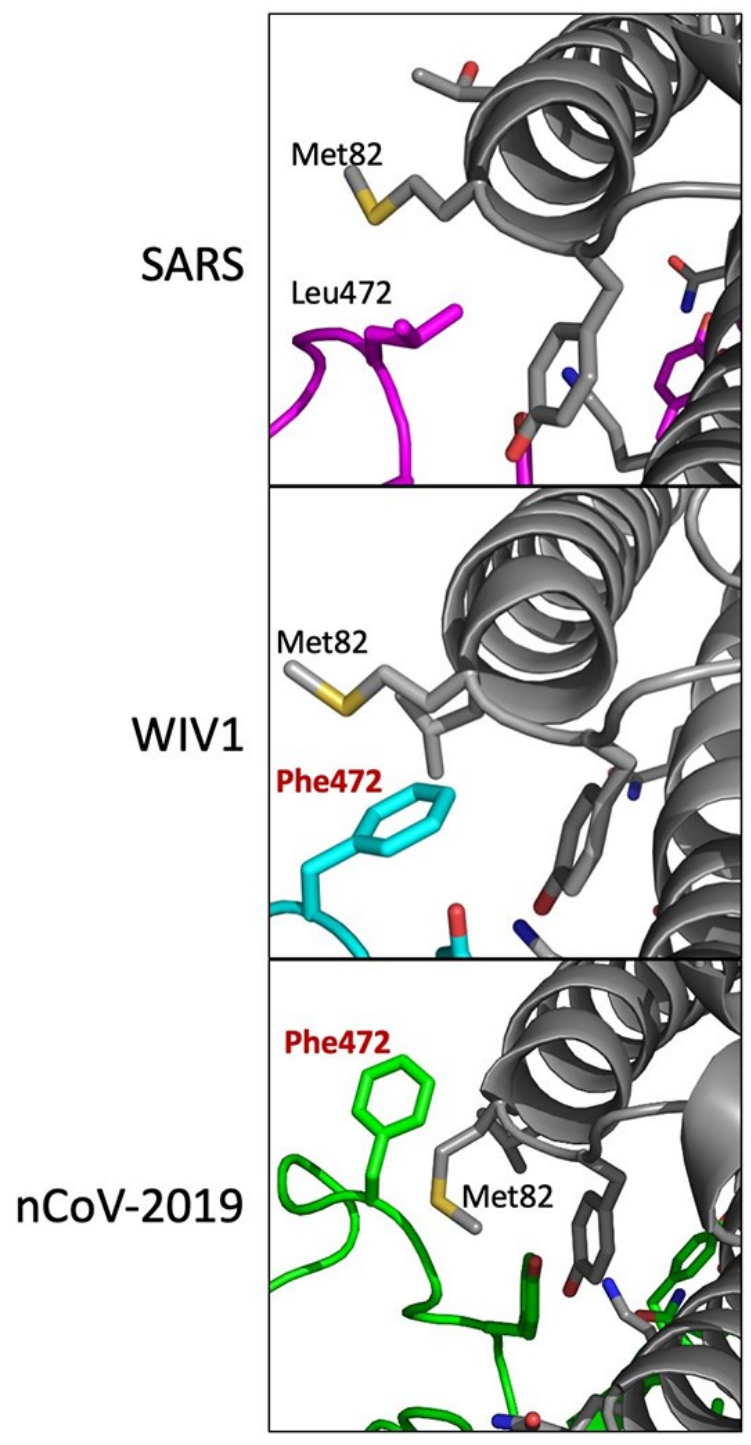

Asn479

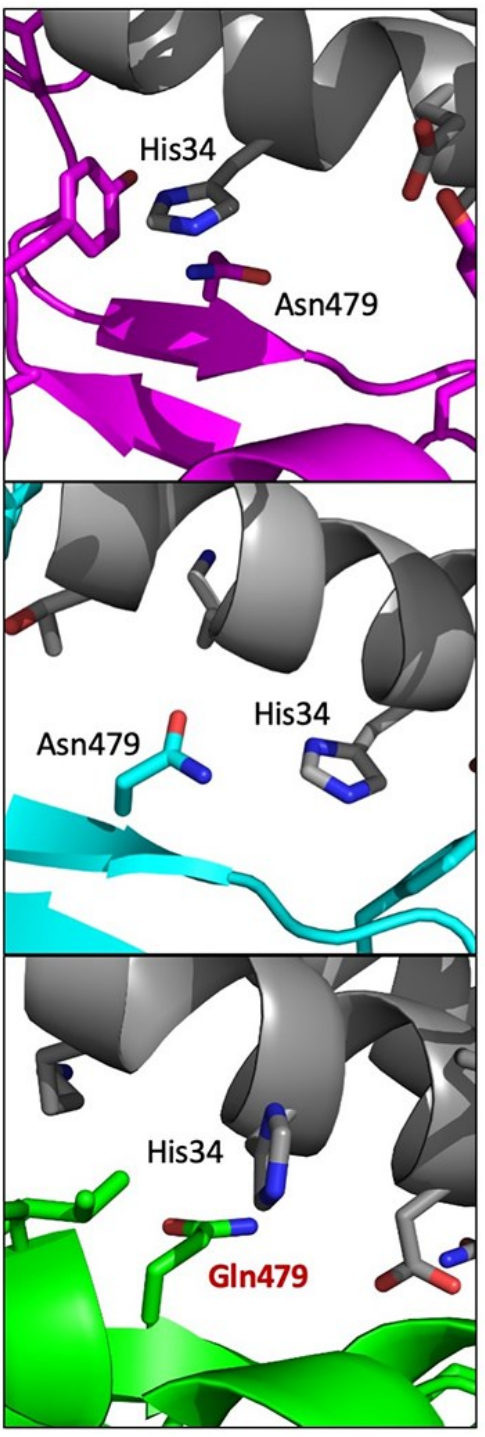

Thr487

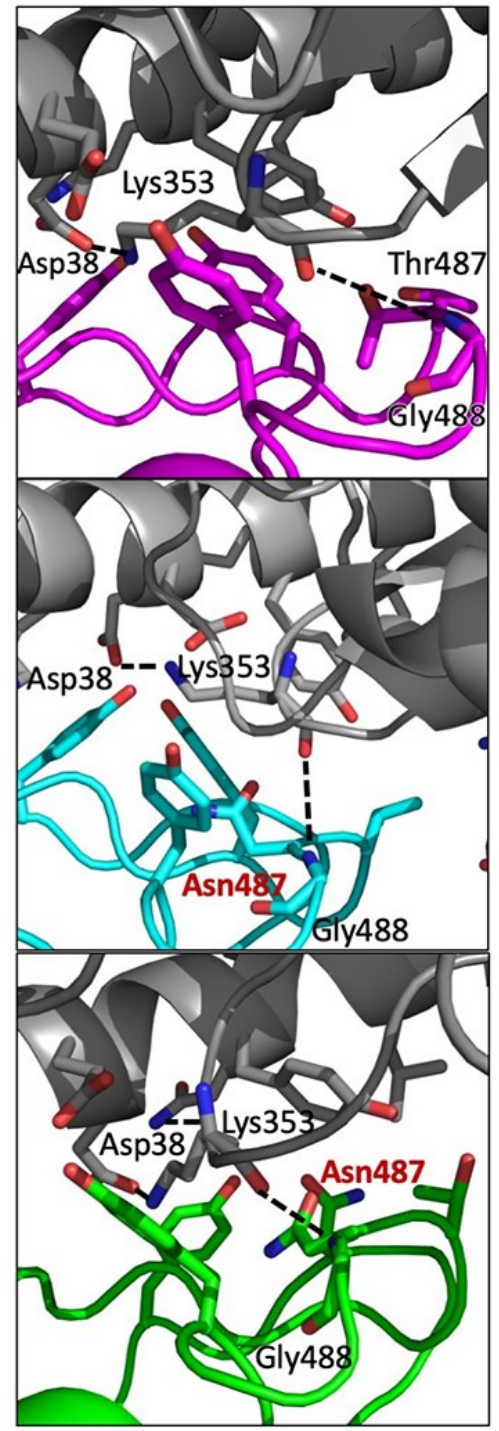

ACE2 is shown in grey and ACE2 residues involved with each of the three RBD residues are shown in stick form. The SARS-CoV, WIV1-CoV, and 2019nCoV RBD homology models are shown in magenta, cyan, and green, respectively. Amino acids involved in ACE2 binding are shown in stick representation in their respective colours. If a SARS-RBD amino acid is mutated in either WIV1-CoV RBD or 2019-nCoV, it is labelled in red. Hydrogen bonds are shown as dashed black lines. 